\title{
LOCATION OPTIMIZATION OF BIODIESEL PROCESSING PLANT BASED ON ROUGH SET AND CLUSTERING ALGORITHM - A CASE STUDY IN CHINA
}

\author{
Nana Geng ${ }^{1 *}$ - Yong Zhang ${ }^{1}-$ Yixiang Sun ${ }^{2}$ \\ ${ }^{1}$ School of Transportation, Southeast University, Nanjing, 210018, China \\ ${ }^{2}$ School of Civil Aviation, Nanjing University of Aeronautics and Astronautics, Nanjing, 211106, China
}

\begin{tabular}{l}
\hline ARTICLE INFO \\
\hline Article history: \\
Received: 25.9 .2018$. \\
Received in revised form: 7.6 .2019$. \\
Accepted: 17.6 .2019$. \\
\hline Keywords: \\
Biofuel \\
Supply chain \\
Rough set theory \\
Clustering algorithm \\
\hline DOI: http://doi.org/10.30765/er.40.3.11
\end{tabular}

\section{Introduction}

With the rapid consumption of primary energy all over the world, the existing non-renewable energy

\begin{abstract}
:
Biofuel has an important role in alleviating the environmental pollution problem. More attention has been paid to optimization of biofuel supply chain in recent years. In this paper, a scientific, rational and practical biodiesel processing plant location with waste oil as the raw material was proposed in order to provide a theoretical basis for guiding the planning and management of restaurants, waste oil collection points, and processing plants. Considering the merits and demerits of the subjective and objective weighting methods, this paper proposes a new weighting method which is namely the combination of rough set theory and clustering algorithm. It then verifies the location results with a plant carbon emission. At last, this paper analyzes the location of biodiesel processing plant in the Yangtze River Delta of China and finds that the precision has been greatly improved with the new method comparing the RMSE and the R2 of the Delphi method with the improved rough set theory. By using this method, the weights of the influencing factors of biodiesel processing plants are the following: Waste oil supply 0.143, Fixed construction cost factor 0.343, Biodiesel demand 0.143 and Location convenience 0.371. In the comparison between the robust optimization method and the improved rough set theory, it was found that the final location results are the same, all being Jiaxing City. However, the improved rough set theory is much simpler than the robust optimization algorithm in the calculation process.
\end{abstract}

sources have been faced with the depletion [1]. In response, it is urgent to develop a renewable energy to reduce the dependence on the gradual depletion of resources and the impact on the environment [2]. 
Biofuel becomes an important direction of renewable energy development and utilization with the advantages of low cost and good transportation [3]. Biofuel is fuel that is converted directly or indirectly from biomass raw materials (straw, waste cooking oil) [4]. The distribution of biofuel processing plant is also relatively scattered by the impact of biomass raw material origin [5]. Therefore, how to choose the processing plant location scientifically and rationally is getting more and more attention from experts and scholars all over the world.

Currently, biofuel is divided into bioethanol and biodiesel. Biodiesel is used more in buses and trucks than bioethanol, and its supply chain is relatively mature. From the perspective of investment, biodiesel is more economical as a third-generation energy source [6]. So, this paper chooses biodiesel as the research object. This paper takes Chinese biodiesel processing plant location as the example mainly considering the three aspects: one aspect is comparison with the developed countries. There is a gap between theory and practice of Chinese biodiesel processing plant. Chinese development and utilization of biodiesel are a bit behind. The real large-scale intervention began in 2005[7]. While the United States and some European countries have begun to build the commercial biodiesel production base in the 1990s and their biodiesel has been widely used [8]. Second, biodiesel as an emerging industry, is developing rapidly. In the "13th Five-Year Plan" of Chinese biomass energy development plan until 2020, biomass energy utilization will reach 57 million tons of standard coal, of which the biomass boiler heating will reach 20,000 tons per hour steam. Furthermore, biomass solid fuel utilization will reach 10 million tons of standard coal annual; bio-natural gas will reach 100 billion cubic meters; biomass liquid fuel will reach 6 million tons, of which 4 million tons of bioethanol, 200 million tons of biodiesel [9]. With the increase in demand and production of biodiesel, the requirement for new biodiesel plants location is increased. Third, efficient collection, processing and transportation systems are essential for the efficient use of biodiesel. Therefore, the location of biodiesel collection and biodiesel processing plants are becoming the key issues for the efficient use of biomass resources. The cost of collection, storage, and transportation of raw materials during the processing and operation of biodiesel accounts for a large proportion [10]. In order to minimize the high transport costs and negative environmental impacts, an appropriate biodiesel processing plant location is very necessary.
Construction of biodiesel processing plant location method and model is crucial for the biofuel industry and other complex industries planning. An improved location method is often assumed to be obtained with a complex Linear programming problem with a series of constraints and objectives. However, the Linear programming problem does not take into account some of the qualitative factors that are beneficial for the location process [11]. Thus, in this paper, we proposed a new method that takes both qualitative and quantitative factors into consideration using this method in case of location problem of biodiesel processing plant with waste edible oil as the raw material in 27 cities in the Yangtze River Delta of China.

\section{Literature review}

Facility location problem has long been studied. Many models and algorithms about facility location problem have been developed. In the existing literature, scholars mainly focus on the building of biofuel supply chain optimization model and improved solution method.

- Study on Optimization Model of Biomass Supply

Chain Location Problem

Mitchell provides a detailed review of the relevant models of biomass supply chain and bioenergy conversion before 1999[12]. Mitchell argues that most models tend to deal with one aspect of a bioenergy system rather than the overall optimal one. However, the existing models rarely address the location problem of biofuel processing plant, and most of the models are related to other aspects of bioenergy systems such as biomass conversion technology selection, cost assessment, biomass potential assessment and logistics issues. Madlener used an expert selection method and the AHP method to evaluate the influence factors of CHP (Combined heat and power) system [13]. Tatsiopoulos designed a detailed supply chain model based on cotton stems [14]. Thomas developed a model for potential site location, taking into account the spatial distribution of biomass and the total cost of transportation, and demonstrated that transportation costs could be reduced by $23 \%$ [15]. Bojić proposed a model based on location-based fixed costs and grid capacity constraints to determine the size and type of biomass power plants to minimize generation costs [16]. Ivanov proposed a mixed integer linear programming model for the design of the supply chain and the management of biodiesel logistics [17]. Natarajan 
suggested a national explicit mixed integer linear programming model and applied it to determine the best Fischer-ropsch biodiesel production plant in Finland [18]. Guo used a Conditional Logic Model to build new woody biomass-based facilities such as the intensity of these new policy incentives, the number of resource availability, business tax climates, and the existing labor force that drives the bioenergy industry [19]. Babazadeh brought forward an efficient unified fuzzy data envelopment analysis model to evaluate the performance of the candidate locations for Jutropha curcas L cultivation under uncertainty [20]. Mohseni proposed AHP and RMILP combined model for the design and planning of a microalgaebased biodiesel supply chain [21]. Brusca took microalgae as an example and used GIS that take some important geographical constraints into consideration to simulate optimal locations for sitting microalgae cultivation plants for biofuel production [22].

- Study on the improved solution method for biofuel supply chain location problem

Papadopoulos focused on how biofuel facility sites can reduce biomass logistics costs by using a twostage optimization approach: first, to determine the location of the combined heat and power plant with a minimum transport distance, then using the dynamic programming optimization method to determine the most appropriate biomass fuels [23]. David proposed the use of colony-feeding algorithms to solve the problem of bio-plant location [24]. This method can avoid some accurate algorithm to calculate the result in an unrealistic situation, can help investors to make effective investment decision-making. Zhao suggested the storage location model of the storage center based on the gravity center method and the storage location problem of the enterprise by using the AHP-based storage and storage optimization model [25]. Young used a logistic regression model to study factors influencing the location of bioenergy facilities. They found that raw material richness and the number of infrastructure such as highways had a positive impact on plant location, while regional average household income, population, and labor costs have a negative impact on site selection [26]. Xie introduced a mixed integer programming model and proposed a variety of solutions to solve the multiple plant location problem [27]. Duarte proposed an optimization framework that uses MILP formulas to combine supply chain process design and configuration. The model was used to locate Colombia's second-generation bioethanol plant using agricultural residues called Coffee-CSs [28]. Brusca proposed a centroid mathematical method to optimize the biodiesel production plant placing. Since the article has achieved good results in terms of time and precision, it also helps the regulatory agency in the decision-making process when planning applications. [29]. Delivand used a GIS-MCA approach to minimize the total transport distance and establish an optimal location for the site construction. It also analyzed the effects of logistics costs and GHG emissions on site [30]. $\mathrm{Ng}$ designed a multi-period mixed-integer linear programming model for the design and operational planning of cellulosic biofuel supply chains [31].

In this paper, a new method for location of the biodiesel processing plant is proposed by clustering analysis and rough set method. Only a few studies propose clustering analysis and rough set method to solve facility location problem. Liu proposed a method combining rough set and Delphi to evaluate the location decision [32]. Manzini combines mixedinteger linear programming modeling with cluster analysis, heuristic algorithms, and optimal transportation rules to illustrate an original framework for the design and optimization of facility location and supply chain management [33]. Gao designed the qualitative elements evaluation model of Coal Storage Center Location based on the rough set theory and the group eigenvalue method [34]. Tang used GIS analysis method and fuzzy rough sets method to make site selection decision-making of mechanical parking system in urban areas more reasonable [35].

\section{Methods}

The location process is a multi-attribute decisionmaking process without decision-making attribute, and the important premise of solving multi-attribute decision-making problem is the weight distribution of each attribute. The solution of such problems is usually divided into subjective weighting method and objective weighting method. However, the subjective weight method often requires a lot of prior knowledge, and the evaluation results have some subjective randomness. The objective weighting method sometimes has the problem of missing data and does not fully take into account the importance of each factor in the evaluation of the different degrees. Through the clustering analysis of quantitative data and knowledge reduction of qualitative data to eliminate redundant information and deal with uncertainty information, the weights of influencing 
factors of biodiesel processing plant location should be researched and the location results obtained.

\subsection{Solving steps}

The first step is processing and calculating of the original data to cluster the city's quantitative data. Here we use the system clustering method to process the quantitative data from the 27 cities;

Second, this paper takes the index of biodiesel factory location influencing factors as the condition attributes and also takes the index of experts preference on the biodiesel factory as the decision attribute to construct the decision table;

The third step is to delete the same attribute values that delete the repeated data rows to simplified decision table;

Then, the equivalence classes are divided according to the condition attribute and decision attribute. The importance of the attributes in its set is equal to the changing degree relative to a positive region after removing the attributes. The greater the changing degree, the higher is the attributes importance;

At last, calculation of the index weight. Normalize the important degree of each index to get the weight of each index.

\subsection{The specific steps of the system clustering method}

1) Construct $\mathrm{N}$ classes, each class contains and only contains a sample.

2) Calculate the distance between the $N$ samples, constitute the distance matrix, and record as D.

3) Merge two classes of the nearest distance into a new class.

4) Calculate the distance between the new class and all the current various types. If the number of classes is equal to 1 , go to step 5), otherwise, return to step $3)$.

5) Determine the class numbers and the sample numbers contained in various classes.

The biggest advantages of the system clustering method are that it can cluster both the observed quantity and variable. The variables used can be either continuous variables or classified variables. At the same time, the distance calculation method and the result display method that provide system clustering in SPSS is also very good.

\subsection{Application steps of the rough set theory}

- $K=(X, A, V, f)$ is a knowledge base, $X$ is a nonempty set called the domain. $A=C \cup D$ is a nonempty finite set of properties. $C$ is the decision attribute of D, $C \cap D=\Phi . V_{a}$ is the range of the $a \in A$ attribute. $f: X \times A \rightarrow V$ is an information function which gives an information value of each object.

- Let $X$ be a finite non empty domain, $R$ is the equivalence relation of $X . R$ divides $X$ into several disjoint subsets. Each subset is called an equivalence class, use $[x]_{R}$ to express, $[x]_{R}=\{y \in X \mid x R y\}, x \in X . x, y$ is called the equivalence relation. $X / R$ represent a collection of all equivalent classes set on the domain $X$.

- For $\forall X \subseteq U$ the upper approximation and the lower approximation of dominance relations $R_{B}$ is

$$
\begin{aligned}
\overline{R_{B}}= & \left\{x_{i} \in U \mid\left[x_{i}\right]_{B} \cap X \neq \varnothing\right\}{\underline{R_{B}}}(X) \\
& =\left\{x_{i} \in U \mid\left[x_{i}\right]_{B} \subseteq X\right\}
\end{aligned}
$$

Similarly, the positive domain is defined as

$$
\operatorname{Pos}_{B}(X)=\underline{R_{B}}(X)=\left\{x_{i} \in U \mid\left[x_{i}\right]_{B} \subseteq X\right\}
$$

This represents the elements set which must belong to $B$.

- Make $P$ and $Q$ dominant in relation to $U$, the $P$ Positive region of $Q$ is denoted as

$$
\operatorname{Pos}_{P}(Q)=\bigcup_{X \subseteq U / Q} \underline{P} X
$$

The dependence of $Q$ and $P$ is defined as

$$
\gamma_{P}(Q)=\frac{|\operatorname{Pos} P(Q)|}{|U|}, 0 \leq \gamma_{P}(Q) \leq 1
$$

Different attributes have different importance. In order to find out importance of each attribute, a specific approach is to first remove the attribute, and then observe whether the classification changed in comparison to before under the conditions of no attributes. If this attribute is removed, the corresponding classification change is small, then it shows that the importance of the attribute is low; otherwise, it means the attribute is more important.

- Set ordered information system $S=(\mathrm{U}, \mathrm{A}, \mathrm{V}, f)$,

$$
A=C \bigcup D \text {, and } C \cap D=\varnothing, C \text { and } D \text { are }
$$


respectively the conditional attribute set and the decision attribute set, the importance of attribute subset is defined as:

$$
\eta_{D}(G)=\gamma_{C}(D)-\gamma_{C-G}(D)
$$

When $G=\{c\}$, the importance of attribute $c \in C$ in $D$ is:

$$
\operatorname{Sig}_{D}(a)=\gamma_{C}(D)-\gamma_{C-\{c\}}(D)
$$

\section{China Yangtze River Delta biodiesel processing plant location examples}

\subsection{The Case introduction}

In this paper, 27 Chinese cities of Yangtze River Delta Region are used as candidates for processing plants. We chose five location evaluation indexes that decide the city selection of processing plants: waste oil supply, fixed construction cost, biodiesel demand,

Table 1. The index data of the candidate processing plant

\begin{tabular}{cccccc}
\hline City & $\begin{array}{c}\text { Waste oil } \\
\text { supply }\end{array}$ & $\begin{array}{c}\text { Fixed construction } \\
\text { cost }\end{array}$ & $\begin{array}{c}\text { Biodiesel } \\
\text { demand }\end{array}$ & $\begin{array}{c}\text { Location } \\
\text { convenience }\end{array}$ & $\begin{array}{c}\text { Location } \\
\text { preferences }\end{array}$ \\
\hline Shanghai & 29705 & 4200 & 9136 & 7 & 3 \\
Hefei & 9582 & 2940 & 2947 & 7 & 3 \\
Maanshan & 2782 & 2100 & 856 & 10 & 3 \\
Hangzhou & 8802 & 3780 & 2707 & 7 & 3 \\
Ningbo & 7180 & 3780 & 2208 & 3 & 2 \\
Jiaxing & 4282 & 2520 & 1317 & 7 & 3 \\
Huzhou & 3244 & 2100 & 998 & 7 & 3 \\
Shaoxing & 5449 & 2100 & 1676 & 7 & 3 \\
Zhoushan & 1199 & 2100 & 369 & 3 & 2 \\
Wenzhou & 10008 & 2940 & 3078 & 3 & 2 \\
Jinhua & 5843 & 2100 & 1797 & 3 & 2 \\
Quzhou & 3145 & 2100 & 967 & 3 & 2 \\
Taizhou & 7344 & 2100 & 2259 & 3 & 1 \\
Lishui & 3267 & 2100 & 1005 & 3 & 2 \\
Nanjing & 10106 & 3780 & 3108 & 10 & 2 \\
Wuxi & 7995 & 3360 & 2459 & 7 & 1 \\
Xuzhou & 10613 & 2520 & 3264 & 7 & 1 \\
Changzhou & 5777 & 2520 & 1777 & 10 & 1 \\
Suzhou & 13043 & 3360 & 4011 & 7 & 1 \\
Nantong & 8977 & 2520 & 2761 & 7 & 1 \\
Lianyungang & 5476 & 2100 & 1684 & 7 & 1 \\
Huaian & 5968 & 2520 & 1836 & 7 & 1 \\
Yancheng & 8884 & 2100 & 2732 & 7 & 1 \\
Yancheng & 5508 & 2520 & 1694 & 10 & 1 \\
Zhenjiang & 3901 & 2520 & 1200 & 10 & 1 \\
Taizhou & 5705 & 2100 & 1832 & 755 & 7 \\
Suqian & 5957 & 2100 & & & 1 \\
\hline
\end{tabular}


convenience and location preferences. Then, combined with the qualitative and quantitative data, apply the improved rough set theory, and evaluate the processing plant city in the Yangtze River Delta Region. The data source of this paper is based on the preliminary research and published papers [36].

\subsection{Criterion and evaluation index of biodiesel facility location}

After summarizing the relevant literature on biofuel supply chain problem, this paper includes the influencing factors that affect the location of the processing plants in each city:

1) Fixed construction cost factor: The cost of construction of the processing plants in different regions due to different land prices;

2) Waste oil Supply quantity factor: Number of waste oil supply on a yearly basis in each area;

3) Biodiesel demand factor: Number of biodiesel's demands on a yearly basis in each area, a producer price index, measuring the average changes in prices received by the domestic producers for their output;

4) The convenience factor: convenience perceived indicators of supply chain members, measuring the effectiveness of biodiesel processing plants supply chain. The measurement of this indicator mainly considers the proximity, accessibility and convenience of the biodiesel processing plant and the cargo hub;

5) The location preference factor: the expert confidence index, measuring optimism that experts are expressing through their experience and practice activities. The measurement of this indicator mainly considers the impact of cost, market, government and other factors from the perspective of biodiesel processing plant.

According to the above factors, this paper uses fixed construction cost, waste oil supply quantity, biodiesel demand, convenience degree and location preference as the location evaluation indexes of oil and diesel processing plant to perform the following study.

\subsection{Data discretization processing based on a clustering algorithm}

Here, the convenience index is made by the expert scoring. The higher score represents the better convenience degree. Biodiesel processing plants location preferences are also made by the expert scoring. The higher scores indicate the high degree experts, tending to build a processing plant here.

The following is the reduction of data, using the cluster analysis method. The detailed steps are the cluster analysis with SPSS21.0, reduction and classification of the index data. Through data discretization and attribute value reduction, delete the same sample attribute values and obtained the simple decision in Table 2.

In order to facilitate the following calculation, this paper uses a, b, c, d, e instead of the corresponding index in Table 2. "A" is for waste oil supply, while "b" is for the fixed construction cost of the biodiesel refining plant. "C" is for biodiesel demand, while " $\mathrm{d}$ " is for the convenience of the biodiesel refining plant location, and "e" is for location preference of e biodiesel refining plant. Also, we use 1 27 numbers to instead the 27 cities in the Yangtze River Delta.

\subsection{Weight determination of evaluation index based on rough set theory}

The equivalence class partition and the weights are determined again. According to the condition attribute and decision attribute, the data domain in Table 2 is divided into two parts:

$$
\begin{aligned}
& U / \operatorname{IND}(C)= \\
& \left\{\begin{array}{l}
\{1\},\{2\},\{3\},\{4\},\{5\},\{6\},\{7\},\{8\},\{9\},\{10\},\{11\}, \\
\{12\},\{13\},\{14\},\{15\},\{16\},\{17\},\{18\},\{19\},\{20\}, \\
\{21\},\{22\},\{23\},\{24\},\{25\},\{26\},\{27\}
\end{array}\right\} \\
& U / \operatorname{IND}(D)=\left\{\begin{array}{l}
\{1,2,3,11,13,15,27\}, \\
\{4,5,8,12,16,17,18,19,21,23,24\}, \\
\{6,7,9,10,14,20,22,25,26\}
\end{array}\right\}
\end{aligned}
$$

Then, after removing one condition attribute in turn, the domain equivalence type is divided as follows:

$$
\begin{aligned}
& U / I N D\left(C-C_{1}\right)= \\
& \left\{\begin{array}{l}
\{1\},\{2,4,19\},\{3\},\{5\},\{5\},\{6,22\},\{10\}, \\
\{7,8,24,26,27\},\{9,11,12,13,14\}, \\
\{15\},\{16\},\{17,20\},\{18,24,25\},\{23\}
\end{array}\right\} \\
& U / I N D\left(C-C_{2}\right)= \\
& \left\{\begin{array}{l}
\{1\},\{2,4,17,19,20\},\{3,18,24,25\}, \\
\{5,9,12,13,14\},\{6,22,7,8,21,26,27\}, \\
\{10\},\{11\},\{15\},\{16\},\{17\}
\end{array}\right\}
\end{aligned}
$$


$U / \operatorname{IND}\left(C-C_{3}\right)=$
$\left\{\begin{array}{l}\{1\},\{2,4,19\},\{3\},\{5\},\{7,8,21,23,26,27\}, \\ \{9,12,13,14\},\{10\},\{11\},\{15\},\{16\},\{17\}, \\ \{18,24,25\},\end{array}\right\}$

$U / \operatorname{IND}\left(C-C_{4}\right)=$ $\left\{\begin{array}{l}\{1\},\{2,4,10,15,19\}, \\ \{3,7,8,9,12,13,14,21,26,27\},\{5,16\}, \\ \{6,18,22,24,25\},\{11\},\{17,20\},\{23\},\end{array}\right\}$

The positive domain of the decision attribute under each condition attribute is:

$$
\begin{aligned}
& \operatorname{POC}_{C}=\left\{\begin{array}{l}
1,2,3,4,5,6,7,8,9,10,11,12,13, \\
14,15,16,17,18,19,20,21,22, \\
23,24,25,26,27
\end{array}\right\} \\
& \operatorname{POC}_{C-C_{1}}=\left\{\begin{array}{l}
1,\{2,419\}, 3,5,6,22,\{7,8,21,26,27\}, \\
23,\{16,17,20,15\}, 10
\end{array}\right\} \\
& P O C_{C-C_{2}}=\{1,10,11,15,23\} \\
& \operatorname{POC}_{C-C_{3}}=\left\{\begin{array}{l}
1,\{2,4,19\}, 3,5,\{9,12,13,14\}, \\
10,11,15,16,\{17,20\}
\end{array}\right\} \\
& P O C_{C-C_{4}}=\{1,11,\{17,20\}, 23\}
\end{aligned}
$$

\begin{tabular}{|c|c|c|c|c|c|}
\hline City & $\begin{array}{l}\text { Waste oil } \\
\text { supply }\end{array}$ & $\begin{array}{c}\text { Fixed construction } \\
\text { cost }\end{array}$ & $\begin{array}{c}\text { Biodiesel } \\
\text { demand }\end{array}$ & $\begin{array}{c}\text { Location } \\
\text { convenience }\end{array}$ & $\begin{array}{c}\text { Location } \\
\text { preferences }\end{array}$ \\
\hline 1 & 10 & 3 & 10 & 10 & 3 \\
\hline 2 & 7 & 3 & 7 & 7 & 3 \\
\hline 3 & 3 & 10 & 3 & 10 & 3 \\
\hline 4 & 7 & 3 & 7 & 10 & 2 \\
\hline 5 & 7 & 3 & 3 & 7 & 2 \\
\hline 6 & 3 & 7 & 3 & 7 & 1 \\
\hline 7 & 3 & 10 & 3 & 10 & 1 \\
\hline 8 & 3 & 10 & 3 & 10 & 2 \\
\hline 9 & 3 & 10 & 3 & 3 & 1 \\
\hline 10 & 7 & 3 & 7 & 7 & 1 \\
\hline 11 & 3 & 10 & 3 & 7 & 3 \\
\hline 12 & 3 & 10 & 3 & 3 & 2 \\
\hline 13 & 7 & 10 & 3 & 7 & 3 \\
\hline 14 & 3 & 10 & 3 & 7 & 1 \\
\hline 15 & 7 & 3 & 7 & 10 & 3 \\
\hline 16 & 7 & 3 & 3 & 10 & 2 \\
\hline 17 & 7 & 7 & 7 & 7 & 2 \\
\hline 18 & 3 & 7 & 3 & 7 & 2 \\
\hline 19 & 7 & 3 & 7 & 7 & 2 \\
\hline 20 & 7 & 7 & 7 & 7 & 1 \\
\hline 21 & 3 & 10 & 3 & 7 & 2 \\
\hline 22 & 3 & 7 & 3 & 3 & 1 \\
\hline 23 & 7 & 10 & 7 & 3 & 2 \\
\hline 24 & 3 & 7 & 3 & 3 & 2 \\
\hline 25 & 3 & 7 & 3 & 10 & 1 \\
\hline 26 & 7 & 10 & 3 & 7 & 1 \\
\hline 27 & 3 & 10 & 3 & 3 & 3 \\
\hline
\end{tabular}

Table 2. Decision-making values after the reduced attributes 
The approximation precision of each condition attribute set with respect to decision attributes are:

$$
\begin{gathered}
r_{C}(D)=\frac{\left|P O S_{C}(D)\right|}{|U|}=\frac{15}{27} \\
r_{C-C_{1}}(D)=\frac{\left|P O S_{C-C_{1}}(D)\right|}{|U|}=\frac{10}{27} \\
r_{C-C_{2}}(D)=\frac{\left|P O S_{C-C_{2}}(D)\right|}{|U|}=\frac{5}{27} \\
r_{C-C_{3}}(D)=\frac{\left|P O S_{C-C_{3}}(D)\right|}{|U|}=\frac{10}{27} \\
r_{C-C_{4}}(D)=\frac{\left|P O S_{C-C_{4}}(D)\right|}{|U|}=\frac{4}{27}
\end{gathered}
$$

The importance of each condition attribute on decision attributes:

$$
\begin{aligned}
& \operatorname{Sig}_{D}\left(C_{1}\right)=r_{C}(D)-r_{C-C_{1}}(D)=\frac{5}{27} \\
& \operatorname{Sig}_{D}\left(C_{2}\right)=r_{C}(D)-r_{C-C_{2}}(D)=\frac{10}{27} \\
& \operatorname{Sig}_{D}\left(C_{3}\right)=r_{C}(D)-r_{C-C_{3}}(D)=\frac{5}{27} \\
& \operatorname{Sig}_{D}\left(C_{4}\right)=r_{C}(D)-r_{C-C_{4}}(D)=\frac{11}{27}
\end{aligned}
$$

After normalization processing, we get the importance of $C_{1} C_{2} C_{3} C_{4}$. They are 0.185; 0.444; 0.185 and 0.481 respectively. That is to say the corresponding waste oil supply, fixed construction costs, the biodiesel demand, and the location convenience weight are respectively $0.143 ; 0.343$; $0.143 ; 0.371$.

Using the weights obtained by the improved rough set, we can calculate the location results, and get the first rank city: Jiaxing. This is consistent with the results obtained using the robust optimization method for the same data in the same case, but the computational procedure is much simpler. Therefore, in the future practice of research, there will be more use of value.

\section{The method validation}

Since biodiesel is a low-carbon green fuel, if its raw material collection points, processing plants, distribution centers and other have an improper location, it will result in not only lack of the environmental protection function, but its whole supply chain carbon emissions increased. Therefore, carbon emissions can be used as an important indicator, which can reflect whether the processing plants site is reasonable, or not. In this paper, the carbon emissions data from the previous research is located. Firstly, sum up the results of the index weights obtained by the Delphi method and multiply with the scores of the indicators. Use the same computing method to sum up the results of index weights obtained by the second calculation of the

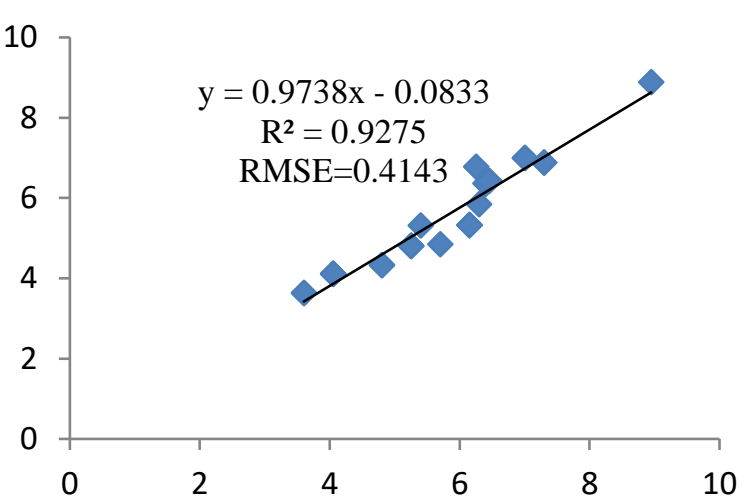

Figure 1. Relationship between the location results and carbon emissions from biofuel processing plants calculated by the rough set theory

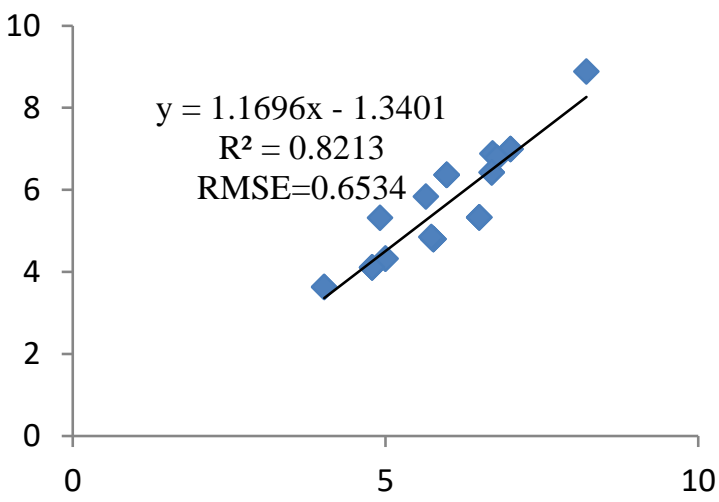

Figure 2. Relationship between location results and carbon emissions from biofuel processing plants calculated by the Delphi method

rough set theory multiplied with the scores of the indicators. Then the results of these two methods were compared with the carbon emission results of the location. $\left(\mathrm{R}^{2}\right)$ and root means square error (RMSE) are used to judge the accuracy of the evaluation results and the rationality of the index weight is reflected. From Figures 1 and 2, it is shown that the results obtained by the rough set theory and the Delphi method are both above 0.8 . This indicates that both approaches have achieved significant levels. While $\mathrm{R}^{2}$ result obtained by the new method as shown in Figure 1 is 0.9275 , which is more relevant to the carbon emission. From Figure 1, we can see the RMSE result obtained by the new method as 0.4143 , 
which is smaller than the Delphi method. The results show that the weight coefficient of each index can be determined more accurately by the rough set algorithm after the original data is contracted by the clustering algorithm.

\section{Conclusion}

The main contribution of this paper is to propose a more scientific and reasonable method to guide the location of qualitative data and quantitative data and to provide a reference for biodiesel processing plant decision makers. Furthermore, it also minimizes economic losses and the waste of resources due to a blind location. Then, by using the improved rough set theory and the Delphi method, the paper analyzes the relativity of the carbon emissions of the sample cities. The results show that:

First, the use of this method analyzes a large number of historical data, and we can get to the extent of the condition attributes affecting the decision attributes, that is, the weights of the influencing factors of biodiesel processing plants are respectivly: 0.143; $0.343 ; 0.143 ; 0.371$. The final location result is Jiaxing, which is in the same place calculated by the robust optimization method in the same case.

Second, the improved rough set theory is feasible in the application of the location problem of biodiesel processing plants. Because of its advantages in eliminating errors caused by the subjective judgment and dealing with uncertain information, it is more reasonable and accurate to determine the weight of each index comparing it with the Delphi method. This can provide a useful idea for the location of biodiesel processing plant and related fields.

Of course, this article also has many shortcomings, for example, with any location. The first important thing is the determination of location index. While this paper is just based on the experience and fulfilling a simple survey, obviously, this has been unable to meet the increased volatiles. It is necessary to carry on more in-depth research on the location index and location method and provide more useful decision-making information for decision makers.

\section{Acknowledgements}

This work was supported by the Funding of Jiangsu Innovation Program for Graduate Education (KYLX15_0312).

\section{References}

[1] Omer, A.M., Energy, Environment and Sustainable Development, Renewable and sustainable energy reviews, 12(2008), 9, 22652300.

[2] Twidell, J., Weir, T., Renewable energy resources, Routledge, PA: Tayloy \& Francis. 2015.

[3] Johari, A., Nyakuma, B.B., Nor, S.H.M., Mat, R., Hashim, H., Ahmad, A., Zakaria, Z.Y., Abdullah, T.A.T., The challenges and prospects of palm oil based biodiesel in Malaysia. Energy, 81(2015), 255-261.

[4] Chiu, C.C., Shiang, W.J., Lin, C.J., Wang, C.H., Chang, D.M., Water footprint analysis of second-generation bioethanol in Taiwan, Journal of Cleaner Production, 101(2015), 271277.

[5] Jiang, Y., Zhang, Y., Supply chain optimization of biodiesel produced from waste cooking oil, Transportation Research Procedia, 12(2016), 938-949.

[6] Glavan I. Prelec Z., The analysis of trigeneration energy systems and selection of the best option based on criteria of ghg emission, cost and efficiency. Engineering Review, 32(2012), 3, 131-139.

[7] Ma, G. P., Zhang, Y., Discussions on Current Situation and Problems of Biomass Energy Development in China, Management of Agricultural Science and Technology, 3(2013),1,20-25. (In Chinese)

[8] Wang,C.W., Cui,F.F., Song,Y., Research situation and development prospect of biodiesel, China Oils and Fats, 39 (2014),.5, 44-48.

[9] Outline of the $13^{\text {th }}$ Five-Year Plan for Economic and Social Development of the People's Republic of China. National Development and Reform Commission, http://www.ndrc.gov.cn/gzdt/201603/P0201603 18576353824805.pdf

[10] Marchetti, J. M., Miguel, V. U., Errazu, A. F., Techno-economic study of different alternatives for biodiesel production, Fuel Processing Technology, 89(2008),8, 740-748.

[11] Amin, S. H., Razmi, J., Zhang, G., "Supplier selection and order allocation based on fuzzy SWOT analysis and fuzzy linear programming", Expert Systems with Applications, 38(2011),1,334-342. 
[12] Mitchell, C., Development of decision support systems for bioenergy applications, Biomass and Bioenergy, 18(2000),4,265-278.

[13] Madlener, R., How to Maintain Competition and Diversity Asocio - ecological - economic assessment of bioenergy options with a focus on CHP, Socio-economic aspects of bioenergy systems:Challenges and opportunities, 2011.

[14] Tatsiopoulos, I., Tolis, A., Economic aspects of the cotton-stalk biomass logistics and comparison of supply chain methods, Biomass and Bioenergy, 24(2003), 3,199-214.

[15] Voets, T., Neven, A., Thewys, T, Kuppens, T., GIS-BASED location optimization of a biomass conversion plant on contaminated willow in the Campine region (Belgium), Biomass and Bioenery, 55(2013), 339-349.

[16] Bojić, S., Đatkov, Đ., Brcanov, D., Georgijević, M., Martinov, M., Location allocation of solid biomass power plants: Case study of Vojvodina, Renewable and Sustainable Energy Reviews, 26(2013), 769-775.

[17] Ivanov, B., Dimitrova, B., Dobrudzhaliev, D., Optimal Location of Biodiesel Refineries: The Bulgarian Scale, Journal Of Chemical Technology \& Metallurgy, 48(2013), 5, 513-523

[18] Natarajan, K., Leduc, S., Pelkonen, P., Tomppo, E., Dotzauer, E., Optimal locations for second generation Fischer Tropsch biodiesel production in Finland, Renewable Energy: An International Journal, 62(2014), 319-330.

[19] Zhimei, Guo, Donald, G. Hodges., Timothy, M. Young., Woody biomass policies and location decisions of the woody bioenergy industry in the southern United States, BIOMASS AND BIOENERGY,56(2013), 268-273.

[20] Babazadeh, R., Razmi, J., Pishvaee, M., Sustainable cultivation location optimization of the Jatropha curcas L. under uncertainty: A unified fuzzy data envelopment analysis approach, Measurement, 89(2016), 252-260.

[21] Mohseni, S., Pishvaee, M., Sahebi, H., Robust design and planning of microalgae biomass-tobiodiesel supply chain: A case study in Iran, Energy. 111(2016),736-755.

[22] Brusca S, Famoso F, Lanzafame R, Messina M, Wilson J (2017). A site selection model to identify optimal locations for microalgae biofuel production facilities in sicily (Italy), International Journal of Applied Engineering Research, 12, 16058-16067.

[23] Papadopoulos, D., Katsigiannis, P., Biomass energy surveying and techno-economic assessment of suitable CHP system installations, Biomass and Bioenergy, 22(2002),2, 105-124.

[24] Vera D., Carabias, J., Jurado, F., Ruiz, R.N., A Honey Bee Foraging approach for optimal location of a biomass power plant, Applied Energy, 87(2010),7,2119-2127.

[25] Zhao,T., Zhang, G.C., Sun, F., Study of location and optimization of biomass raw materials, transportation and store, Chinese Agricultural Mechanization, 12(2012), 194-197.

[26] Young, T. M., Zaretski, R.L., Perdue, J.H., Guess, F.M., Liu, X., Logistic regression models of factors influencing the location of bioenergy and biofuels plants, Bio Resources, 6(2011),1,329-343.

[27] Xie, W., Ouyang, Y., Dynamic Planning of Facility Locations with Benefits from Multitype Facility Colocation, Computer-Aided Civil \& Infrastructure Engineering, 28(2013),9, 666-678

[28] Duarte, A., Sarache, W., Costa, Y., A facilitylocation model for biofuel plants: Applications in the Colombian context, Energy,72(2014), 476-483.

[29] Brusca S, Famoso F, Lanzafame R, Messina M, Monforte P (2017). Placement optimization of biodiesel production plant by means of centroid mathematical method, Energy Procedia, 126, 353- 360 .

[30] Delivand, M.K., Cammerino, A.R.B., Garofalo, P., Monteleone, M., Optimal locations of bioenergy facilities, biomass spatial availability, logistics costs and GHG emissions: a case study on electricity productions in South Italy, Journal of Cleaner Production, 15(2015), 235-242.

[31] Ng, R.T., Maravelias, C.T., Design of biofuel supply chains with variable regional depot and biorefinery locations, Renewable Energy: An International Journal, 100(2017), 90-102.

[32]LIU, L., ZHENG, G.H., LIU, J. and ZHOU, A.F., Location Selection of Logistics Park Based on Integrating Rough Set with Fuzzy Delphi, Logistics Technology. 27(2008),1,37-40.

[33] Manzini, R., Bindi, F., Strategic design and operational management optimization of a multi stage physical distribution system, Transportation Research: Part E, 45(2009), 6, 915-936.

[34] GAO, T.G., CHEN P.Y., MA, S.Y, ZHAO, W.M., Method Research of Coal Storage Center Location Based on Roughset and Group Eigenvalue, Journal of Wuhan University of Technology, 34 (2012), 4,531-534. 
[35] Tang, M., Wang, X., Cao, J., Li, Y., Sun, Z., Site selection decision-making with GIS for mechanical parking system based on mutual information attribute reduction, Xitong Gongcheng Lilun $\mathrm{Yu}$ Shijian (Systems Engineering Theory \& Practice), 35(2015),1, 175-182.
[36]Zhang, Y., Jiang, Y., Zhong, M., Geng, N., Chen, D., Robust Optimization on Regional WCO-forBiodiesel Supply Chain under Supply and Demand Uncertainties, Scientific Programming, 8(2016),1-15. 